emergency services arrive. People who overdose, and their friends and family, could be given supplies of naloxone to keep at home and could be trained to give lifesaving interim care. ${ }^{\mathrm{w} 2 \mathrm{w} 3}$ Naloxone is already approved for reversing opiate overdoses. About $10 \%$ of user distributed naloxone is used for resuscitation-an informal project in Chicago reports 440 "reversals" from 6000 doses distributed (D Bigg, personal communication, 2006), and no fatalities or adverse reactions have yet been reported. The novelty is in the different settings and people giving naxolone.

Doctors are the primary group able to prescribe and administer naloxone. But many people who take overdoses die before the doctor arrives. Naloxone is already approved for use by ambulance services, similar to giving thrombolysis and defibrillation for suspected myocardial infarction. Some nurses and pharmacists can now give naloxone, under new "patient group directions" in the UK. ${ }^{\mathrm{w}}{ }^{4}$ Doctors can instruct patients in self administration, as well as instructing family or other carers in emergency care or drug rehabilitation houses. Naloxone can be prescribed to named patients for self administration (this is an orthodox doctor-patient relationship, analogous to prescribing antivenin or emergency adrenaline). However, most opiate misusers are incapacitated by the time they realise they are overdosing. Named patients, with named carer, relative, or friend trained in its administration, can be prescribed naloxone (as with emergency adrenaline for anaphylaxis or glucagon for hypoglycaemia). Prescription to named patients, who themselves train another in assessing overdose and giving naloxone, is also possible, making naloxone more widely available but less controllable for clinicians. All these approaches are already being used within different clinical services in different localities.

Within our own clinical services, we currently target two groups, both with a high incidence of overdose: detoxified opiate misusers being discharged back into the community, ${ }^{\mathrm{w}}$ and patients in the first few weeks of methadone substitution therapy. ${ }^{\mathrm{w} 6}$ We also plan to provide naloxone to former opiate misusers being released from prisons, in view of their recognised excess mortality. ${ }^{\mathrm{w} 7}$

Three proposals should be considered to increase the availability of naloxone. Firstly, further training should be provided in emergency administration of naloxone by non-healthcare staff. Non-healthcare staff in police stations, prisons, rehabilitation hostels, or remote communities could be trained in recognising and managing overdoses (as aircrew are trained in managing in-flight emergencies) and could even receive instruction by mobile phone.

Secondly, patients or carers could administer naloxone to others who have a heroin overdose. If a patient or carer, trained in use of naloxone, is called to a life threatening heroin overdose, then they could potentially save a life by administering naloxone while waiting for emergency services to arrive. Although we do not currently recommend this, as it is unclear where the boundaries of duty of care lie, we are hearing from trained patients, carers, and staff who have given naloxone to others and judged it to have been life saving.

Thirdly, in the future, perhaps naloxone should be available over the counter in pharmacies, needle exchange programmes, and voluntary agencies to reach those at risk who are not in treatment. This would make it more available but would require further legislation, and the public would need training.

Naloxone is an extraordinarily effective drug and has been "transferred" to ambulance crews. The next logical transfer is for take-home naloxone to be given to patients at risk, their families, and carers (see bmj.com) to prevent deaths in the critical minutes before specialist care arrives.

\section{John Strang director}

(j.strang@iop.kcl.ac.uk)

Michael Kelleher consultant psychiatrist in the addictions David Best honorary senior lecturer in the addictions Soraya Mayet specialist registrar in the addictions Victoria Manning research worker in the addictions

National Addiction Centre (Institute of Psychiatry/The Maudsley), London SE5 8AF

Competing interests: None declared.

Sporer KA. Strategies for preventing heroin overdose. $B M$ 2003;326:442-4.

White JM Irvine RJ. Mechanisms of fatal opioid overdose. Addiction 1999;94:961-72.

Roberts I, Barker M, Li L. Analysis of trends in deaths from accidental drug poisoning in teenagers, 1985-95. BMJ 1997;315:289.

Kelleher M, Keown P, O'Gara C, Keaney F, Farrell M, Strang J. Dying for Kelleher M, Keown P, O'Gara C, Keaney F, Farrell M, Strang J. Dying for
heroin: the increasing opioid-related mortality in the Republic of Ireland, 1980-1999. Eur J Pub Health 2005;15:589-92.

5 Medicines for Human Use (Prescribing) (Miscellaneous Amendments) Order 2005. www.opsi.gov.uk/si/si2005/20051507.htm (accessed 28 Jun 2006)

6 Strang J, Powis B, Best D, Vingoe L, Griffiths P, Taylor C, et al. Preventing opiate overdose fatalities with take-home naloxone: pre-launch study of possible impact and acceptability. Addiction 1999;94:199-204.

Strang J, Best D, Man L-H, Noble A, Gossop M. Peer-initiated overdose resuscitation: fellow drug users could be mobilised to implement overdose resuscitation. Int J Drug Policy 2000;11:437-45.

\title{
Teratogenicity of antiepileptic drugs
}

Women should consider stopping, minimising, or switching drugs before pregnancy

$\mathrm{P}$ rescribing for women with epilepsy is complicated by the potential teratogenicity of antiepileptic drugs. Current guidelines recommend that the most effective drug should be chosen before conception and prescribed at its lowest effective dose, ideally as monotherapy. ${ }^{12}$ But which antiepileptic drug is safest in pregnancy?
Early research on the safety of antiepileptic drugs in pregnancy was unreliable. Several countries set up pregnancy registries in the late 1990s, and data from these registries are now appearing.

References w1-w6 are on bmj.com 
To date the UK Epilepsy and Pregnancy Registry has recruited more than 3500 women, of whom $72 \%$ were given antiepileptic monotherapy. The overall rate of major congenital malformation in women given antiepileptic drugs during pregnancy was $4.2 \%$, compared with $3.5 \%$ in women with epilepsy who were not given such drugs. ${ }^{3}$ By three months of age, infants exposed to sodium valproate monotherapy during gestation had the highest frequency of major congenital malformation $(6.2 \%)$, confirming similar findings from an Australian register. ${ }^{4}$ Lamotrigine monotherapy was associated with a $3.2 \%$ frequency of malformation, but in a multivariate analysis this frequency was not significantly different from that seen with valproate monotherapy. The risk with lamotrigine at doses above $200 \mathrm{mg}$ a day was similar to that of valproate doses of $\leq 1000 \mathrm{mg} /$ day. Carbamazepine was associated with the lowest frequency of major congenital malformation (2.2\% for monotherapy). Polytherapy with antiepileptic drugs was associated with a significantly higher frequency of major malformation than monotherapy $(6 \%$ v $3.7 \%)$.

The North American Pregnancy Registry found that valproate monotherapy was associated with a $10.7 \%$ frequency of major congenital malformation. This represents an increased relative risk of 7.3 compared with a control group from one US teaching hospital's malformation surveillance programme. ${ }^{5}$ The US registry had previously reported an increased risk of malformation in babies exposed to phenobarbital ${ }^{6}$-an important finding as this antiepileptic drug is still widely used in many countries.

These registries provide observational data only, and include many variables (such as type of epilepsy, seizure frequency, and drug compliance) that may influence results. Furthermore, major congenital malformations are defined differently by each registry, so results are not directly comparable.

The potential for antiepileptic drugs to cause developmental delay in childhood is even more difficult to measure than major congenital malformation. Adab and colleagues found that valproate monotherapy in pregnancy was associated with decreased verbal IQ when compared with carbamazepine or phenytoin monotherapy, and that this was dose related. ${ }^{\mathrm{w} 1}$ They also reported that $30 \%$ of children exposed to valproate needed special educational support in school, compared with $3-6 \%$ of those exposed to monotherapy with other antiepileptic drugs. ${ }^{\mathrm{w} 2}$ Similar results were reported in a Finnish study.w3 A further study has, however, shown adverse neurodevelopmental effects in children exposed to a variety of antiepileptic drugs during gestation, not only valproate. ${ }^{\mathrm{w} t}$ The neurodevelopment effects of antiepileptic drugs (NEAD) study is currently investigating behavioural outcomes in children exposed to antiepileptic drugs in pregnancy (www.neuro.mcg.edu/np/ NEAD.htm).

Overall, evidence shows that valproate is associated with a higher frequency of major congenital malformation than other antiepileptic drugs and seems more likely to cause neurodevelopmental delay. Carbamazepine is associated with the lowest incidence of major congenital malformation, while lamotrigine is probably not as safe as previously thought. No reliable data are available on the safety of most of the newer antiepileptic drugs in pregnancy.
What does all of this mean for doctors and their patients? Ideally, women with epilepsy should plan pregnancy in advance and discuss this with their doctor and epilepsy nurse. All women should take folic acid $5 \mathrm{mg}$ a day before conception and for at least the first trimester of pregnancy.

Doctors should consider whether individual patients need antiepileptic drugs at all during pregnancy. Women with focal seizures alone, women who have been seizure-free for at least two years, or women who have infrequent generalised seizures may prefer to stop their antiepileptic drugs, but this must be assessed on an individual basis. If treatment is needed during pregnancy, carbamazepine seems to be the safest option.

While most authorities recommend either valproate or lamotrigine as first line treatment for idiopathic generalised epilepsy, little evidence exists to support this notion, ${ }^{\mathrm{w} 5}$ except that some types of epilepsy-such as juvenile myoclonic epilepsy-may be exacerbated by carbamazepine. Women already established on valproate or high dose lamotrigine face a difficult decision when planning pregnancy. Their options include maintaining current treatment, lowering the dose as far as possible, or considering swapping to carbamazepine. Women taking more than one drug should consider switching to monotherapy, although many do not alter their antiepileptic drug regimen during pregnancy. ${ }^{\mathrm{w} 6} \mathrm{In}$ practice, many pregnancies are unplanned, so doctors and epilepsy nurses should discuss this issue with all women of childbearing potential when epilepsy is first diagnosed.

It remains to be seen whether any of the newer antiepileptic drugs will prove to be less teratogenic. In the meantime, we should use the best available evidence to guide our decisions and the advice we give to women with epilepsy, and reassure them that they are likely to have a successful uncomplicated pregnancy.

David P Breen foundation year 2 doctor in colorectal surgery

(davebreen@lycos.com)

Department of Colorectal Surgery, Western General Hospital, Edinburgh EH4 2XU

\section{Richard J Davenport consultant neurologist}

Department of Clinical Neurosciences, Western General Hospital, Edinburgh EH4 2XU

Competing interests: RJD has received consultancy fees or speaker's fees (or both) from Pfizer (gabapentin, phenytoin), GSK (lamotrigine), Janssen Cilag (topiramate), and Sanofi (valproate). 1 Commission on Genetics, Pregnancy and the Child, International ing age with epilepsy. Epilepsia 1993;34:588-9.

2 Adab N, Tudur SC, Vinten J, Williamson P, Winterbottom J. Common antiepileptic drugs in pregnancy in women with epilepsy. Cochrane Database Syst Reu 2004;(3):CD004848.

3 Morrow JI, Russell A, Gutherie E, Parsons L, Robertson I, Waddell R, et al. Malformation risks of anti-epileptic drugs in pregnancy: a prospective study from the UK Epilepsy and Pregnancy Register. J Neurol Neurosurg Psychiatry 2006;77:193-8.

4 Vajda FJ, O'Brien TJ, Hitchcock A, Graham J, Cook M, Lauder C, et al. Critical relationship between sodium valproate dose and human Critical relationship between sodium valproate dose and human
teratogenicity: results of the Australian register of anti-epileptic drugs in teratogenicity: results of the Australian register of anti-epileptic drugs in pregnancy.J Clin Nernosci $2004,11: 854-8$.

Wyszynski DF, Nambisan M, Surve T, Alsdorf RM, Smith CR, Holmes LB. Increased rate of major malformations in offspring exposed to valproate during pregnancy. Neurology 2005;64:961-5.

6 Holmes LB, Wyszynski DF, Lieberman E. The AED (Antiepileptic Drug) Pregnancy Registry: a 6-year experience. Arch Neurol 2004;61:673-8.

doi 10.1136/bmj.38961.437639.BE 